Revue d'histoire de l'Amérique française

REVUE D.HISTOIRE DE L'AMÉRIQUE FRANÇAISE

ROSS, Sally et J.-Alphonse DEVEAU, Les Acadiens de la

Nouvelle-Ecosse hier et aujourd'hui (Moncton, Éditions

d'Acadie, 1995), 293 p.

\title{
Josette Brun
}

Volume 50, numéro 4, printemps 1997

URI : https://id.erudit.org/iderudit/305610ar

DOI : https://doi.org/10.7202/305610ar

Aller au sommaire du numéro

Éditeur(s)

Institut d'histoire de l'Amérique française

ISSN

0035-2357 (imprimé)

1492-1383 (numérique)

Découvrir la revue

Citer ce compte rendu

Brun, J. (1997). Compte rendu de [ROSS, Sally et J.-Alphonse DEVEAU, Les

Acadiens de la Nouvelle-Écosse hier et aujourd'hui (Moncton, Éditions d'Acadie,

1995), 293 p.] Revue d'histoire de l'Amérique française, 50(4), 629-630.

https://doi.org/10.7202/305610ar d'utilisation que vous pouvez consulter en ligne.

https://apropos.erudit.org/fr/usagers/politique-dutilisation/ 
ROSS, Sally et J.-Alphonse DEVEAU, Les Acadiens de la Nouvelle-Écosse hier et aujourd'hui (Moncton, Éditions d'Acadie, 1995), 293 p.

L'historiographie acadienne s'est enrichie d'un nouvel ouvrage, soit la traduction française par les Éditions d'Acadie du livre sur les Acadiens de la Nouvelle-Écosse (The Acadians of Nova Scotia, Past and Present, 1992) écrit par Sally Ross et J.-Alphonse Deveau. Cet ouvrage destiné au grand public apporte une contribution importante à la compréhension de l'histoire acadienne de la Nouvelle-Écosse, particulièrement pour la période qui suit la Déportation. Il reflète deux tendances de l'historiographie acadienne récente, soit l'écriture d'une histoire plurielle et l'intérêt grandissant porté par les historiens à l'Acadie des $\mathrm{XIX}^{\mathrm{e}}$ et $\mathrm{XX}^{\mathrm{e}}$ siècles.

Le récit, qui débute avec l'installation des Français sur les rives de la baie française (baie de Fundy) au XVII ${ }^{e}$ siècle et se rend jusqu'au dernier quart du $\mathrm{XX}^{\mathrm{e}}$ siècle, est divisé en deux parties, division marquée par le moment de rupture que représente la déportation des Acadiens. Les auteurs visent d'abord à jeter un regard neuf sur une partie de l'histoire acadienne qui a fait couler beaucoup d'encre, soit l'Acadie d'avant le Grand Dérangement, puis de faire ressortir les particularités de la minorité francophone de la Nouvelle-Écosse des $\mathrm{XIX}^{\mathrm{e}}$ et $\mathrm{XX}^{\mathrm{e}}$ siècles, tout en soulignant les différences qui caractérisent les diverses régions acadiennes.

Les trois premiers chapitres font le survol de la première tranche de l'histoire acadienne. Cette section, largement descriptive, est la plus faible de l'ouvrage. Afin de rendre plus vivante l'histoire des débuts de l'Acadie, les auteurs ont puisé dans les textes des explorateurs et des pionniers (Cartier, Champlain, Lescarbot, Denys...) et autres documents d'époque (recensements, journal de voyage de Dièreville). Il en résulte cependant une utilisation descriptive et peu critique de certains documents qui devraient plutôt servir à illustrer des traits de société autrement analysés. Par contre, les auteurs utilisent avec bonheur les résultats des fouilles archéologiques récentes qui lèvent le voile sur la vie matérielle, les habitudes alimentaires et les activités commerciales des habitants de l'Acadie aux $\mathrm{XVII}^{\mathrm{e}}$ et $\mathrm{XVIII}{ }^{\mathrm{e}}$ siècles 
et sur une société plus complexe que celle décrite par l'historiographie traditionnelle.

Le défi que se sont lancé les deux auteurs a été relevé avec brio dans la dernière partie qui met l'accent sur la question de la survivance de la langue française et de la culture acadienne aux $\mathrm{XIX}^{\mathrm{e}}$ et $\mathrm{XX}^{\mathrm{e}}$ siècles. Le premier chapitre traite du lent retour des Acadiens en Nouvelle-Écosse, qui s'étend du milieu des années 1760 à la fin des années 1780, et qui mène à la formation graduelle de nouveaux villages acadiens. Les régions fertiles autrefois exploitées par les Acadiens ayant été prises par les colons (les Planters) venus de la Nouvelle-Angleterre, les Acadiens ont dû se disperser dans sept régions principales de la Nouvelle-Écosse actuelle: Argyle; Clare; Chéticamp; l'île Madame; Pomquet, Tracadie et Havre-Boucher; Chezzetcook; Minudie, Nappan et Maccan. L'histoire de chaque région et l'évolution de sa culture acadienne ont été modelées par la nature des migrations acadiennes, ellesmêmes conditionnées par les réseaux de parenté et le mode de concession des terres, et par la composition ethnique des villages. Ainsi, la langue française n'a pu survivre à l'influence de la langue anglaise majoritaire dans les deux dernières régions situées dans les comtés de Cumberland et d'Halifax tandis que l'importance et l'homogénéité du bassin de population acadienne dans la région de Clare et l'isolement de la communauté acadienne de la région de Chéticamp y ont favorisé la survivance de la culture acadienne.

Le dernier chapitre traite des choix et des défis qui se sont posés aux Acadiens de la Nouvelle-Écosse au $\mathrm{XX}^{\mathrm{e}}$ siècle, tout particulièrement depuis la fin des années 1960. Si peu d'Acadiens parlent anglais au début du siècle, la situation est tout autre à la veille du $\mathrm{XXI}^{\mathrm{e}}$ siècle. Les ravages de l'assimilation se font sentir chez cette minorité d'origine française qui représentait dix pour cent de la population de la province au début du siècle puisque, aujourd'hui, moins de la moitié se dit francophone. Les Acadiens de la Nouvelle-Écosse ont cependant profité des retombées des luttes menées par les francophones du Québec et du Nouveau-Brunswick depuis les années 1960. À la faveur d'un climat politique plus favorable à l'endroit des francophones, les Acadiens néo-écossais ont obtenu des gains importants sur le plan législatif dans le domaine de l'éducation en français, perçu comme étant le moyen par excellence de contrer l'assimilation. Les organismes acadiens ont cependant dû faire face à des obstacles de taille dont l'inaction du gouvernement et l'apathie des parents acadiens reflétant des siècles de domination par la majorité anglophone. À l'ère des communications de masse dominées par la culture anglo-américaine, la question de la survivance de la culture acadienne se pose de façon cruciale dans une province où les enfants anglophones qui suivent des cours d'immersion en français sont plus nombreux que les enfants acadiens fréquentant l'école française. 